\title{
Urban Distribution Mode Selection under Low Carbon Economy-A Case Study of Guangzhou City
}

\author{
Lei Yang *, Yiji Cai, Jiahui Hong, Yongqiang Shi and Zhiyong Zhang \\ School of Economics and Commerce, South China University of Technology, Guangzhou 510006, China; \\ cai.yiji@mail.scut.edu.cn (Y.C.); hong.jiahui@mail.scut.edu.cn (J.H.); yqshi@scut.edu.cn (Y.S.); \\ zhyzhang@scut.edu.cn (Z.Z.) \\ * Correspondence: yang@scut.edu.cn; Tel.: +86-20-3938-1128
}

Academic Editor: Tan Yigitcanlar

Received: 18 April 2016; Accepted: 8 July 2016; Published: 15 July 2016

\begin{abstract}
In the transformation of urban distribution industry, the problem of enterprises generally retaining a self-distribution mode is highlighted, and it is not conducive for enterprises to develop core business. Around the hot issue of climate change, but also the target of energy conservation and emission reduction, this paper puts forward the method of urban distribution mode to reduce carbon emission intensity, introduces four kinds of typical urban distribution mode, analyzes the core influencing factors of urban distribution mode, studies the carbon accounting method of urban distribution, put forwards the method of low carbon urban distribution mode, analyzes the current situation of the distribution of Guangzhou City, determines the main research types of goods, and applies the method proposed in this paper to the specific enterprises. Urban distribution mode integration and carbon emissions intensity reduction are both considered in this work. The specific application result of $11.28 \%$ reduction on carbon emission intensity shows that this method can effectively guide enterprises to develop low carbon urban distribution mode and reduce carbon emission intensity of urban distribution.
\end{abstract}

Keywords: low carbon economy; urban distribution mode; carbon accounting; carbon emission intensity; fuzzy analytic hierarchy process

\section{Introduction}

With the acceleration of urbanization, the world's population is increasingly concentrated in the city, and the world's urban population will increase from 3.6 billion in 2011 to 6 billion in 2050 [1]. Moreover, the economic in China is growing rapidly and the pace of urban construction is moving fast. In 2012, the Ministry of Commerce selected nine pilot cities to organize urban distribution exhibition. In 2013, the country added 15 cities to pilot joint distribution. The transport Ministry, in the "Transport Twelfth five-year development plan", strengthens the construction of regional distribution centers. After the development of the "urban logistics vehicle technical requirements", the requirements will be issued in the national implementation. In early 2013, the Ministry of Transport with six ministries jointly issued "On strengthening and improving the management of urban distribution of opinions" and proposed specific guidance in the planning, infrastructure, access control, market supervision and other aspects.

In 2012, the level of urbanization in China has reached 52.57\%. With the rapid development of economic and living standards, it has a tremendous impact on the city production, consumption and transportation. Moreover, the consumption ability improves and transport frequency increases, which aggravates the burden on the city's transport system and brings an enormous challenge to the urban distribution. The demands of urban distribution are increasing and citizens are looking forward to higher distribution efficiency. The original urban transportation system has become increasingly 
unable to keep up with the needs of urban development. On one hand, with the acceleration of urbanization process in China, the growth of vehicle ownership is increasing in the city. Besides the popularity of e-commerce online shopping, the urban distribution pattern of high frequency and the small quantities multi-docking site have developed rapidly. On the other hand, it is difficult to keep up with the pace of urbanization, because of China's relatively backward traffic management and the slow development of urban transport infrastructure. The contradictions between supply and demand of urban transport have become increasingly prominent, gradually exposed some shortcomings like urban traffic congestion, such as Beijing, Shanghai, Guangzhou and other big cities, which have suffered severe traffic congestion.

If the logistics industry is a cardiovascular system, then urban distribution is capillary, directly related to the production and life of supply chain's end. Urban distribution mode is the basic strategy to take for enterprises' urban distribution, which is related to the rational allocation of urban distribution resources. At present, enterprises in each city adopt the self-distribution mode as the main distribution strategy, which is not conducive for small and medium enterprises to develop their core business. Simultaneously, the global have highly focused on climate issues in recent years. Reducing carbon emission intensity has become the primary task in the development of various industries. Urban distribution is the industry with high energy consumption and high emission. Thus, it plays an important role in studying the urban distribution from the perspective of low carbon. The research on urban distribution can not only help enterprises choose better distribution mode and achieve the optimal allocation of resources, but also promote enterprises to develop sustainable low carbon distribution and reduce the intensity of carbon emission.

As urban distribution lacks practical operation experience, the distribution mode urgently needs to be explored. In developed countries, urban logistics common distribution as an advanced logistics organization is widely used, not only for its high-intensive enterprises, which bring significant economic benefits, improve the efficiency of logistics operations, reduce social burden and environmental pollution, but also because of the future logistics and distribution trends. However, in China, the common distribution develops slowly, the overall operation is relatively extensive. Domestic joint distribution researches are not enough. In addition, it is difficult to implement common distribution in business operations. Self-distribution, third party distribution and mutual distribution are still the mainstream for urban distribution.

Abroad, early actions of carbon emission reduction in developed economies would have a significant impact on climate change, and these countries need to accelerate the pace of emission reduction with respect to the developing countries [2]. Several neighboring cities in the EU implemented innovative eco logistics systems in the last 50 years, and the carbon dioxide emissions decreased by $84 \%$ under the same conditions, which significantly reduced the impact on the environment [3]. With the environmental problems being paid more attention, the research of the reverse logistics network design and inventory model has gradually increased [4-7]. For the periodic inventory review system, reduce the frequency of shipment can promote the realization of emission reduction targets, but the cost of emission reduction and unit holding costs are not necessarily linked [8].

Researches from multiple factors to consider emission reductions are as follows. They consider the economic costs and carbon emissions, which can improve the sustainability performance of logistics and supply chain management [9-11]. Since lean logistics improves system flexibility, transportation-related carbon emissions will reduce while the facility-related emission increases. In business process reengineering changes, it needs to be considered in this regard [12]. Siting and path planning researches are as follows: they try to ensure that the maximum goods are transported at minimum mileage, which can save $4.9 \%-6.9 \%$ of the fuel consumed [13]. With the gradual promotion of clean energy vehicles, city vehicles need to distinguish between path planning, environment-friendly vehicles and non-environmentally friendly vehicle to improve the original algorithm [14]. Considering low-carbon factors in the Multi Distribution Center Location can reduce carbon emissions [15]. 
Combined weighted linear combination and improved Dijkstra algorithm, environment and logistics cost can be subdivided into multiple standards to solve problem in GIS, it is reasonable to study the green path planning of urban logistics centers [16]. In reference to the new technology researches, with the LCA software UMBERTO we find that cascade utilization technology is able to reduce the logistics network of carbon dioxide gradually [17]. We take the carbon tax into urban distribution network planning model, it is able to reduce carbon dioxide emissions by $54.5 \%$ [18]. Through the implementation of a carbon tax and other ways to improve energy efficiency, we ensure that China will implement the target of carbon intensity 40\%-45\% lower in 2020 [19]. We need to recognize that the application of information technology can contribute to sustainable development of urban road freight, but it is not obvious to reduce carbon emissions [20,21]. In summary, to reduce urban carbon emissions has a variety of distribution channels, such as vehicle routing, clean energy vehicles, optimizing the distribution network and information technology.

With the rapid development of the economy, China undoubtedly releases large amounts of carbon dioxide. With respect to the reduction of carbon emissions, this paper pays more attention to reducing carbon emissions in the unit value of the corresponding output, which is carbon emissions strength. The study finds that carbon emissions and economic growth are far from constituting a prime linear relationship [22], it means that the carbon emission intensity can be adjusted and changed. From a macro perspective, carbon intensity emission is associated with land use structure. Energy consumption, carbon emissions, energy intensity and carbon intensity are four different but linked concepts. Analysis of these trends evolved plane data distribution for sustainable development, which can provide recommendations for each region [23]. To some extent, how to control the carbon intensity belongs to China featured content development, which is a major goal in China's development of low carbon emissions economy and the researches in this field are few in foreign literature. Thus, this study aims to discuss low-carbon urban distribution pattern problem.

From the point of mathematical modeling, the evaluation method based on the analytic hierarchy process is an auxiliary tool for logistics decision making [24]. The mathematical modeling method consists of affinity diagram, analytic hierarchy process and fuzzy TOPSIS, which can effectively evaluate the sustainable benefits of urban logistics initiatives [25]. Moreover, the fusion of the last two methods can also be used to select the reverse logistics contractors, which have multiple criteria [26]. The combination of fuzzy Delphy and analytic hierarchy process can effectively identify and analyze the priority level of the barriers in reverse logistics [27]. Urban distribution mode is a strategy for enterprise distribution and it will have a significant impact on all aspects of the enterprise. The decision-making process needs to consider many factors, so the method taking analytic hierarchy process as the main body can be used to select the urban distribution mode. At the same time, due to the uncertainty of human thinking, this paper will use the improved fuzzy analytic hierarchy process to analyze the problem of urban distribution mode.

An introduction to the FAHP theory is mainly presented in the second part. Firstly, it analyzes the basic principle of fuzzy matrix consistency checking and improved algorithm. Secondly, it is the introduction of four kinds of typical urban distribution mode and analysis of the main influencing factors. Thirdly, it is the study on urban distribution carbon accounting method. Finally, it proposes the method of low carbon urban distribution mode. We then analyze the present situation of the distribution in Guangzhou City, combined with the definition of carbon emission intensity of urban distribution, which further determines the main research types of goods. The third part uses the method proposed to the specific enterprises, and the results are analyzed and discussed, whose specific calculation process can be found in supplementary material. The fourth part is the conclusion, and summarizes the research results and the future needs in-depth study of the content. 


\section{Fuzzy Matrix on Urban Distribution Selection}

\subsection{Fuzzy Matrix Consistency Checking and Improved Algorithm}

Fuzzy theory is used to make a decision in fuzzy analytic hierarchy process. The steps are the same, including a clear goal, building multi-level structure system, establishing fuzzy complementary judgment matrix, fuzzy complementary judgment matrix consistency test, hierarchical single ranking and hierarchical total ranking.

Suppose domain $X^{m}=\left\{x_{i}^{m} \mid i \in L\right\}$ is the limited set of factors in the $m$ layer, where $L=\{1,2, \ldots, l\}$, and $x_{i}^{m}$ represents the $i$ th factor of the $m$ layer. For the $n$ factors in the $X^{m}$ dominated by the same factor $x_{q}^{m-1}$ in the $m-1$ layer $(n \leqslant l)$, the two elements' fuzzy relation of pairwise comparison is expressed by the following fuzzy complementary judgment matrix.

$$
C^{x_{q}^{m-1}}=\left(c_{i j}^{x_{q}^{m-1}}\right)_{n \times n}(\forall i, j \in N), N=\{1,2, \ldots, n\}
$$

Here, element $c_{i j}^{x_{q}^{m-1}}$ represents the importance of $x_{i}^{m}$ relative to $x_{j}^{m}$ for the dominant factor $x_{q}^{m-1}$, and its value uses the scale of 0.1-0.9. It is known that the greater the $c_{i j}^{x_{q}^{m-1}}$ is, the more important is $x_{i}^{m}$ than $x_{j}^{m}$; the smaller the $c_{i j}^{x_{q}^{m-1}}$ is, the more important is $x_{j}^{m}$ than $x_{i}^{m}$.

According to the above definition, the necessary and sufficient conditions of matrix $C^{x_{q}^{m-1}}$ for a fuzzy complementary judgment matrix are as follows.

(1) $c_{i i}^{x_{q}^{m-1}}=0.5$;

(2) $c_{i j}^{x_{q}^{m-1}}+c_{j i}^{x_{q}^{m-1}}=1(q \leqslant k, \forall i, j \in N), N=\{1,2, \ldots, n\}$.

If the fuzzy complementary judgment matrix $C^{x_{q}^{m-1}}$ satisfies Equation (2), then $C^{x_{q}^{m-1}}$ is called to meet the additive consistency.

$$
c_{i j}^{x_{q}^{m-1}}=c_{i p}^{x_{q}^{m-1}}+c_{p j}^{x_{q}^{m-1}}-0.5(\forall i, j, p \in N)
$$

Therefore, according to the definition of fuzzy complementary judgment matrix, after we satisfy both the properties and conditions of consistency, we can conduct the measure index of consistency: $\rho^{x_{q}^{m-1}}$ and the definition is shown as Equation (3). To meet the consistency, the necessary and sufficient condition of matrix $C^{x_{q}^{m-1}}$ should be $\rho^{x_{q}^{m-1}}=0$. However, as long as $\rho^{x_{q}^{m-1}}$ is not more than a given threshold $\varepsilon$ under normal circumstances $(\varepsilon>0$, decided by the decision maker). In this paper, $\varepsilon=0.1$.

$$
\rho^{x_{q}^{m-1}}=\frac{2}{n(n-1)(n-2)} \times \sum_{i=1}^{n-1} \sum_{j=i+1}^{n} \sum_{\substack{p=1 \\ p \neq i, j}}^{n}\left|c_{i j}^{x_{q}^{m-1}}-\left(c_{i p}^{x_{q}^{m-1}}+c_{p j}^{x_{q}^{m-1}}-0.5\right)\right|
$$

First of all, we introduce the deviation symbol $\delta_{i j p}^{x_{q}^{m-1}}$, and the definition is shown as Equation (4). According to the properties of the fuzzy complementary judgment matrix, it is easy to know:

$$
\begin{aligned}
& \delta_{i j p}^{x_{q}^{m-1}}=-\delta_{j i p}^{x_{q}^{m-1}}=\delta_{j p i}^{x_{q}^{m-1}}=-\delta_{p j i}^{x_{q}^{m-1}}=\delta_{p i j}^{x_{q}^{m-1}}=-\delta_{i p j}^{x_{q}^{m-1}} \\
& \delta_{i j p}^{x_{q}^{m-1}}=c_{i j}^{x_{q}^{m-1}}-\left(c_{i p}^{x_{q}^{m-1}}+c_{p j}^{x_{q}^{m-1}}-0.5\right)(\forall i, j, p \in N)
\end{aligned}
$$


In this paper, only one pair of elements is adjusted at each time. Try to meet the requirements of Equation (5).

$$
\left(c_{i j}^{x_{q}^{m-1}}-\left(c_{i p}^{x_{q}^{m-1}}+c_{p j}^{x_{q}^{m-1}}-0.5\right)\right)\left(\left(c_{i j}^{x_{q}^{m-1}}\right)^{\prime}-\left(c_{i p}^{x_{q}^{m-1}}+c_{p j}^{x_{q}^{m-1}}-0.5\right)\right) \geqslant 0(p \in N, p \neq i, j)
$$

With the goal to improve the consistency of fuzzy judgment matrix, it should decrease the sum of the absolute value for the same element $c_{i j}^{x_{q}^{m-1}}$. The sum of the absolute deviation value differs between former and latter, shown as Equation (6).

$$
\begin{aligned}
& \sum_{\substack{p \neq i, j \\
p \in N}}\left|\left(\delta_{i j p}^{x_{q}^{m-1}}\right)^{\prime}\right|-\sum_{\substack{p \neq i, j \\
p \in N}}\left|\delta_{i j p}^{x_{q}^{m-1}}\right|=\sum_{\substack{p \neq i, j \\
p \in N}}\left|\left(c_{i j}^{x_{q}^{m-1}}\right)^{\prime}-\left(c_{i p}^{x_{q}^{m-1}}+c_{p j}^{x_{q}^{m-1}}-0.5\right)\right|-\sum_{\substack{p \neq i, j \\
p \in N}}\left|c_{i j}^{x_{q}^{m-1}}-\left(c_{i p}^{x_{q}^{m-1}}+c_{p j}^{x_{q}^{m-1}}-0.5\right)\right| \\
& =\sum_{p \in A}\left(\left(c_{i j}^{x_{q}^{m-1}}\right)^{\prime}-c_{i j}^{x_{q}^{m-1}}\right)+\sum_{p \in B}\left(c_{i j}^{x_{q}^{m-1}}-\left(c_{i j}^{x_{q}^{m-1}}\right)^{\prime}\right)=n_{1}\left(\left(c_{i j}^{x_{q}^{m-1}}\right)^{\prime}-c_{i j}^{x_{q}^{m-1}}\right)+n_{2}\left(c_{i j}^{x_{q}^{m-1}}-\left(c_{i j}^{x_{q}^{m-1}}\right)^{\prime}\right) \\
& =\left(n_{1}-n_{2}\right)\left(\left(c_{i j}^{x_{q}^{m-1}}\right)^{\prime}-c_{i j}^{x_{q}^{m-1}}\right)
\end{aligned}
$$

Here, $A=\left\{p \mid \delta_{i j p}^{x_{q}^{m-1}}>0, p \in N, p \neq i, j\right\} ; B=\left\{p \mid \delta_{i j p}^{x_{q}^{m-1}}<0, p \in N, p \neq i, j\right\} ; n_{1}$ represents the number of positive deviations $\delta_{i j p}^{x_{q}^{m-1}} ; n_{2}$ represents the number of negative deviations $\delta_{i j p}^{x_{q}^{m-1}}$.

If it meets the condition: $\left(n_{1}-n_{2}\right)\left(\left(c_{i j}^{x_{q}^{m-1}}\right)^{\prime}-c_{i j}^{x_{q}^{m-1}}\right)<0$, then the consistency correction is valid. It means, numerical positive and negative of $n_{1}-n_{2}$ and $\left(c_{i j}^{x_{q}^{m-1}}\right)^{\prime}-c_{i j}^{x_{q}^{m-1}}$ are not the same. Meanwhile, the bigger the $\left|\left(n_{1}-n_{2}\right)\right|$ and $\left|\left(c_{i j}^{x_{q}^{m-1}}\right)^{\prime}-c_{i j}^{x_{q}^{m-1}}\right|$ are, the easier to approach consistency. Therefore, we need to consider two kinds of circumstances: if $\left(n_{1}-n_{2}\right)>0$, then $\left(c_{i j}^{x_{q}^{m-1}}\right)^{\prime}-c_{i j}^{x_{q}^{m-1}}<0$, and we need to lower the value of the element $c_{i j}^{x_{q}^{m-1}}$ and ensure $c_{i j}^{x_{q}^{m-1}} \neq 0.1$; Similarly, if $\left(n_{1}-n_{2}\right)<0$, we need to enlarge the value of the element $c_{i j}^{x_{q}^{m-1}}$ and $c_{i j}^{x_{q}^{m-1}} \neq 0.9$. Therefore, we can get the complete process of fuzzy judgment matrix consistency checking and improving algorithm.

\subsection{Typical Urban Distribution Modes}

Distribution mode is the basic strategy and method of distribution. Any kind of urban distribution mode need to be formed through repeated exploration and practice, and the urban distribution mode, which is designed by imagination, is not feasible. There are four kinds of typical distribution modes: self-distribution mode, mutual distribution mode, third party distribution mode and common distribution mode.

- $\quad$ Self-distribution mode. Industrial and commercial enterprises build their own distribution system alone, organize and manage each link of distribution. The ownership and management right of distribution system belong to the enterprise. It only serves the enterprise itself, which has a strong capital turnover capacity and distribution scale.

- Mutual distribution mode. Based on the benefit, some enterprises reach an agreement in the form of contract, and use each other's distribution system. Ownership of the distribution system belongs to the original enterprise, and the enterprises share the right to operate. It does not need to invest a lot of manpower and capital, but need strong management, organization and coordination ability. Focus on improving their distribution functions. 
- Third party distribution mode. In addition to the two sides of the transaction, the professional distribution company completes the distribution. The ownership and management right of distribution system belongs to the professional distribution enterprise. The third party does not own the goods, but provides distribution agent services constrained by contract for customers.

- Common distribution mode. In order to improve the distribution efficiency and realize the rationalization of distribution, the distribution enterprises establish the consortium of complementary functions. Members of the commonwealth have common interests and goals, mutual benefit, equality and voluntary. To avoid administrative interference, the aim is to strengthen the distribution function and service to the society, and the stability is stronger.

What needs to be paid attention is that the self-distribution mode represents an important direction of the traditional logistics. Third party distribution mode is wider in modern logistics, but it does not mean the self-distribution mode is backward, and that the third party distribution mode is advanced. The reason why any kind of urban distribution mode can be widely used in the society is that it is in line with the economic development and the strategic objectives of the enterprise. Only when the distribution mode cannot adapt to the demand, is it necessary to optimize the distribution mode.

\subsection{Study on the Carbon Accounting Method of Urban Distribution}

First, defining the boundary of carbon footprint. The specific content of each link in the urban distribution process is shown in Table 1. Carbon emissions come from the energy consumption of facilities and equipment in the distribution process, so the carbon footprint of urban distribution is closely related to the distribution process. Taking into account the division of emission reduction responsibility, China electric power control and platoon bidirectional forced mechanism, this article only accounts for the direct and indirect emissions generated by the service. Therefore, the boundary of urban distribution carbon footprint should be defined as: in the whole service process whose starting point is stocking and ending point is delivery service, from stocking, storage, processing, sorting, picking, and loading, then transport to delivery service, ensure the urban distribution service level and the effective operation of the facilities and equipment. Urban distribution companies consume fuel, purchase electricity and other energy, produce direct and indirect greenhouse gas emissions, which strictly does not include the carbon emissions by the facilities and equipment of packaging products in the urban distribution system with effective support.

Table 1. Every link of urban distribution process.

\begin{tabular}{cl}
$\begin{array}{c}\text { Distribution } \\
\text { Link }\end{array}$ & \multicolumn{1}{c}{ Activity Description } \\
\hline Stocking & According to distribution requirements, cargo collection, receiving, inspection and other management. \\
\hline Storage & $\begin{array}{l}\text { Reserve and Temporary storage. Reserve is to ensure distribution resources to meet requirements, } \\
\text { and temporary storage is to coordinate the time of picking and delivery. }\end{array}$ \\
\hline $\begin{array}{c}\text { Processing } \\
\text { picking }\end{array}$ & $\begin{array}{l}\text { Content is flexible, such as simple packaging, labeling, etc., depending on customer requirements. } \\
\text { according to customer orders, accurately and quickly remove the goods from the storage position, } \\
\text { and sent to a temporary storage area or delivery area. }\end{array}$ \\
\hline Loading & $\begin{array}{l}\text { For cargo whose distribution amount cannot achieve vehicle effective load rate, consider using one } \\
\text { vehicle for loading. }\end{array}$ \\
\hline Transport & $\begin{array}{l}\text { The purpose is to delivery, the distance is short, transportation tools are vehicles and the } \\
\text { scale of cargo is small. }\end{array}$ \\
\hline Delivery service & Coordinate the problem of how to receive the goods after goods are shipped to the destination. \\
\hline
\end{tabular}

Then, focus on emission inventory analysis. Through the detailed analysis of the energy consumption equipment, energy consumption types, greenhouse gas types of the urban distribution process and supporting activities, the results of the inventory analysis are shown in Table 2. Every link of urban distribution process is the main source of energy consumption. Fuel and purchased electricity are the main energy consumption types of city distribution. There are many types of energy consumption equipment. This feature also determines the perspective taken of urban distribution 
carbon footprint accounting in the follow-up study in this paper, and build carbon accounting model according to the classification of energy types.

Table 2. Urban distribution carbon emission inventory.

\begin{tabular}{|c|c|c|c|c|c|}
\hline \multirow{2}{*}{$\begin{array}{l}\text { Distribution Operations } \\
\text { or Supporting Activities }\end{array}$} & \multirow{2}{*}{$\begin{array}{l}\text { Energy Consumption } \\
\text { Equipment }\end{array}$} & \multirow{2}{*}{$\begin{array}{l}\text { Energy Consumption and } \\
\text { Emission Type }\end{array}$} & \multicolumn{3}{|c|}{ Main Greenhouse Gas Type } \\
\hline & & & $\mathrm{CO}_{2}$ & $\mathrm{CH}_{4}$ & $\mathrm{~N}_{2} \mathrm{O}$ \\
\hline Stocking & $\begin{array}{l}\text { Forklifts, barcode } \\
\text { scanners etc. }\end{array}$ & $\begin{array}{l}\text { Fuel and electricity, direct and } \\
\text { indirect emissions }\end{array}$ & $\sqrt{ }$ & $\sqrt{ }$ & $\sqrt{ }$ \\
\hline Storage & $\begin{array}{c}\text { Dehumidification, } \\
\text { ventilation, insulation, } \\
\text { monitoring and other } \\
\text { devices }\end{array}$ & Electricity, indirect emissions & $\sqrt{ }$ & & \\
\hline Processing & Automated equipment & Electricity, indirect emissions & $\sqrt{ }$ & & \\
\hline Sorting and picking & $\begin{array}{l}\text { Automatic sorting } \\
\text { machines, belt } \\
\text { conveyor etc. }\end{array}$ & Electricity, indirect emissions & $\sqrt{ }$ & & \\
\hline Loading & Computers, etc. & Electricity, indirect emissions & $\sqrt{ }$ & & \\
\hline Transport & Distribution vehicles & $\begin{array}{l}\text { Fuel and electricity, direct and } \\
\text { indirect emissions }\end{array}$ & $\sqrt{ }$ & $\sqrt{ }$ & $\sqrt{ }$ \\
\hline Delivery service & $\begin{array}{c}\text { Phones, POS machines, } \\
\text { forklifts, and other } \\
\text { ancillary equipment }\end{array}$ & Electricity, indirect emissions & $\sqrt{ }$ & & \\
\hline Handling & $\begin{array}{c}\text { Internal combustion } \\
\text { and electric handling } \\
\text { equipment }\end{array}$ & $\begin{array}{l}\text { Fuel and electricity, direct and } \\
\text { indirect emissions }\end{array}$ & $\sqrt{ }$ & $\sqrt{ }$ & $\sqrt{ }$ \\
\hline Lighting & Lighting equipment & Electricity, indirect emissions & $\sqrt{ }$ & & \\
\hline
\end{tabular}

Moreover, we build the carbon footprint accounting model. The research on the greenhouse gas emission inventory report is relatively comprehensive, provides reference for the accounting of urban distribution carbon footprint. Referring to the methodology of "2006 IPCC Guidelines for National Greenhouse Gas Inventories" [28], the accounting of urban distribution carbon footprint uses the method of emission factors. According to the results of the emission inventory analysis, the carbon footprint of urban distribution includes two parts.

- Direct greenhouse gas emissions from fuel combustion.

- Indirect emissions resulting from the consumption of purchased electricity.

Therefore, the accounting model of urban distribution carbon footprint is shown as Equation (7).

$$
m=C E_{d}+C E_{i n}=\sum_{l} \sum_{f}\left(A D_{f} \times Q_{f} \times E F_{f, l} \times 10^{-6} \times G W P_{l}\right)+A D_{e} \times E F_{e}
$$

Here, $m$ represents the total amount of greenhouse gases emissions of urban distribution and the unit is $\mathrm{tCO}_{2} \mathrm{e} ; C E_{d}$ represents the total amount of direct greenhouse gas emissions; $C E_{\text {in }}$ represents the total amount of indirect greenhouse gas emissions; $A D_{f}$ represents the consumption amount of fuel $f$ in the statistical period of the enterprise, which is referred to as the activity data; $Q_{f}$ represents the low calorific value of fuel $f ; E F_{f, l}$ represents the emissions factor of greenhouse gas $l$ corresponding to fuel $f ; G W P_{l}$ represents the global warming potential of greenhouse gases $l$, measuring the relative strength of greenhouse gases; $A D_{e}$ represents the amount of purchased electricity the enterprise consuming; $E F_{e}$ represents purchased electricity emission factor. Among them, the reference values of $Q_{f}, E F_{f, l}$, $G W P_{l}$ and $E F_{e}$ are shown as Tables 3-5. 
Table 3. Average low calorific value of fuel and reference value of emission factor.

\begin{tabular}{|c|c|c|c|c|c|c|}
\hline Fuel Type & $\begin{array}{c}\text { Average Low } \\
\text { Calorific Value } \\
\left(\mathrm{MJ} / \mathrm{t} \text { or } \mathrm{MJ} / 10^{4} \mathrm{~m}^{3}\right)\end{array}$ & $\begin{array}{c}\text { Carbon Content } \\
\text { of Unit Calorific } \\
\text { Value [29] } \\
\text { (g-C/MJ) }\end{array}$ & $\begin{array}{l}\text { Carbon } \\
\text { Oxidation } \\
\text { Rate [30] }\end{array}$ & $\begin{array}{c}\mathrm{CO}_{2} \\
\text { Emission } \\
\text { Factor [31] } \\
\left(\mathrm{g} \mathrm{CO}_{2} / \mathrm{MJ}\right)\end{array}$ & $\begin{array}{c}\mathrm{CH}_{4} \\
\text { Emission } \\
\text { Factor [32] } \\
\left(\mathrm{g} \mathrm{CH}_{4} / \mathrm{MJ}\right)\end{array}$ & $\begin{array}{c}\mathrm{N}_{2} \mathrm{O} \\
\text { Emission } \\
\text { Factor [32] } \\
\left(\mathrm{g} \mathrm{N}_{2} \mathrm{O} / \mathrm{MJ}\right)\end{array}$ \\
\hline Gasoline & $43,070[33]$ & 18.9 & 0.98 & 67.9 & 0.033 & 0.0032 \\
\hline Diesel fuel & $42,652[33]$ & 20.2 & 0.98 & 72.6 & 0.0039 & 0.0039 \\
\hline Liquefied petroleum gas & $50,179[33]$ & 17.2 & 0.98 & 61.8 & 0.062 & 0.0002 \\
\hline Liquefied natural gas & $46,900[34]$ & 17.5 & 0.98 & 62.9 & 0.092 & 0.003 \\
\hline Natural gas & $48,000[34]$ & 15.3 & 0.99 & 55.5 & 0.092 & 0.003 \\
\hline
\end{tabular}

Table 4. Value of global warming potential.

\begin{tabular}{cccc}
\hline Greenhouse Gas Type & $\mathbf{C O}_{\mathbf{2}}$ & $\mathbf{C H}_{\mathbf{4}}$ & $\mathbf{N}_{\mathbf{2}} \mathbf{O}$ \\
\hline GWP [35] & 1 & 25 & 298 \\
\hline
\end{tabular}

Table 5. 2008-2014 Purchased electricity emission factor $\left(\mathrm{tCO}_{2} \mathrm{e} / \mathrm{MWh}\right)$.

\begin{tabular}{cccccccc}
\hline Year & $\mathbf{2 0 0 8}$ & $\mathbf{2 0 0 9}$ & $\mathbf{2 0 1 0}$ & $\mathbf{2 0 1 1}$ & $\mathbf{2 0 1 2}$ & $\mathbf{2 0 1 3}$ & $\mathbf{2 0 1 4}$ \\
\hline Purchased electricity emission factor [36] & 1.0634 & 0.9987 & 0.9762 & 0.9489 & 0.9344 & 0.9223 & 0.9183 \\
\hline
\end{tabular}

Note that the collection of consumption activity data such as various fuels and purchased electricity, which still needs to be closely linked to the carbon emissions inventory. They are all the key aspects during activity data collection, in order to record what energy each device consumed and how much consumed. Finally, collect the activity data according to the energy category.

Finally, we definite urban distribution carbon emission intensity. A simple comparison in different statistical period is not representative between different urban distribution modes, which aims to illustrate the difference of the impact on the climate. With the increasing distribution demand of enterprises, the urban distribution will inevitably bring about the rise in total carbon emissions. A better approach is to introduce the revenue of the shipping enterprises during the statistics period and adopt the new indicator: urban distribution carbon intensity (UDCEI). This indicator is the ratio of the total carbon emissions and revenue during the statistics period, which aims to explain the environment impact per revenue of urban distribution. The bigger the value is, the more carbon emissions need to be generated per revenue of distribution enterprise during the statistics period; the smaller the value is, the less carbon emissions need to be generated per revenue of distribution enterprise during the statistics period. Urban distribution carbon emission intensity is determined by Equation (8), UDCEI represents urban distribution carbon intensity during the statistics period, and the unit is $\mathrm{tCO}_{2} \mathrm{e} / 10^{4} \mathrm{CNY}, m$ represents the total amount of greenhouse gases emissions of urban

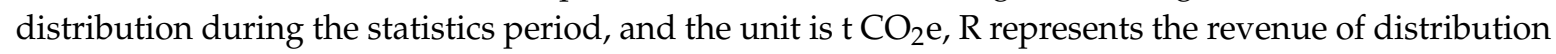
enterprises during the statistics period, and the unit is $10^{4} \mathrm{CNY}$.

$$
U D C E I=m / R
$$

\section{Fuzzy Matrix Model on Urban Distribution}

\subsection{Analysis on Influencing Factors of Urban Distribution Mode}

For companies that have accumulated practical experience in the field of urban distribution, they need to change strategies according to the market, etc. Re-determine the original distribution mode, and make decisions whether to change the distribution mode or not, so as to improve the value in the supply chain. The optimum of urban distribution mode needs to consider multiple factors comprehensively. Therefore, combined with the existing research materials and the characteristics of urban distribution, the main influencing factors are selected and analyzed, which lays the foundation for the optimization of urban distribution mode. 
The development scale and strength of enterprises are the important influencing factors of the urban distribution mode. The comprehensive reflection of the strength, such as market share, operating income, profit margins, information technology and so on, which decides the distribution strategy of the enterprise. Distribution needs to be invested in the construction of infrastructure and the purchase of distribution facilities and equipment. The payback period is long, but it also needs information technology and high-level personnel who have practical experience of distribution management. Enterprise scale strength includes three sub factors: investment risk bearing capacity, information technology level and facilities and equipment level.

- Investment risk bearing capacity. The change of distribution mode needs to have the corresponding investment and the investment must be at risk. Investment risk bearing ability measures whether the enterprise has sufficient funds, relatively stable market share and good prospects for development. It deals and contend with the risks and uncertainties caused by distribution investment.

- Information technology level. Information flow is related to the effective convergence of each link of distribution, and it is the main influencing factor of distribution mode. Information technology level reflects that whether the enterprise has the ability to introduce the information management systems and technologies necessity for distribution or not, as well as the knowledge and professional level of the personnel engaged in information management on the distribution.

- Facilities and equipment level. Distribution activities cannot be separated from the facilities and equipment. The advanced level of the infrastructure such as operating facilities and equipment are the important factors that should be considered in the urban distribution mode.

Enterprises vary in their distribution service capability. Distribution has the essential characteristic of the service and is an important part that cannot be ignored during the time that enterprise completes the whole transaction. Due to the personalized requirements of the customers in different industries supply chain, the differences vary widely, such as the timeliness of distribution, flexibility and other service capacity requirements. As a result, he positioning of the distribution service level differs between different enterprises. Selection of a reasonable urban distribution mode needs to adapt to the distribution services capability of the enterprise. Distribution service capability includes three sub factors: timely accuracy, service flexibility and economic efficiency.

- Timely accuracy. The goal of distribution is to deliver the goods accurately and in a timely manner to the designated location of customer. Accuracy refers to the quality of goods being guaranteed and the number of varieties being accurate. For the distribution of the production material, the requirements of the timeliness and accuracy for client companies are extremely high. Enterprises need to locate the degree of timely accuracy for the services.

- Service flexibility. It measures the ability of enterprises so that the enterprises respond to the temporary change of distribution demand. Customers will always temporarily change the distribution time, the variety and quantity of goods and other key plans for certain reasons. In order to maintain a good relationship with customers, enterprises determine the extent to respond to such changes.

- Economic efficiency. Out of interest, the enterprise pays attention to the management of the distribution cost. Economic efficiency pays attention to the distribution cost of the unit value commodity, which is the factor that enterprises need to consider in choosing the urban distribution mode. Economic efficiency is different to the enterprise on the different development degree.

If the distribution mode of enterprise is consistent with social development trend, the resistance and difficulty of the implementation process are relatively small. Affected by the adjustment of the key direction in the national economic development, the transference of social hot spots and the development trend will change to where the enterprise is located. It is the influential factor of urban 
distribution mode. Social development trend includes three sub factors: distribution policy and regulation, enterprise cooperation ability and low carbon economy development.

- Distribution policy and regulation. Distribution is the function of the logistics close to the end, and it is the key link to solve the problems in people's livelihood. Therefore, the introduction of distribution-related policies and regulations is particularly important. Enterprises need to consider the distribution policy and regulation in the selection, and to achieve the orderly development of distribution under the guidance of policies and regulations.

- Enterprise cooperation ability. The implementation of the urban distribution mode cannot be separated from the cooperation with other enterprises. The level of internal firm cooperation ability affects the selection of urban distribution mode. The enterprise cooperation ability involves the coordination communication ability and the decision control ability to the key question.

- Low carbon economy development. Low carbon economy is a hot spot in the future development of Guangzhou city. The work of energy saving and emission reduction is always the focus. Urban distribution is the key source of carbon emissions and we can achieve emission reduction through optimizing and adjusting the distribution strategy. Therefore, the selection of urban distribution mode needs to consider the factors of low carbon economy development.

\subsection{Researches on Method of Low Carbon Urban Distribution Mode Based on Fuzzy Analytic Hierarchy Process}

On the basis order idea of analytic hierarchy process, this paper proposes the selection method of low carbon urban distribution mode by adding the modified fuzzy matrix consistency method. The whole method consists of seven steps and the details are as follows.

First, make the decision objective clear. The reduction of total energy consumption, total carbon emission and total cost are not the decision objective proposed in this paper. Instead, the decision objective is to choose the best urban distribution mode and reduce the carbon emissions intensity of urban distribution. On one hand, based on the full understanding of all aspects, enterprises personnel re-examine the relative importance of the pair wise of the influencing factors, which realizes the re-judgment and adjustment of enterprises. On the other hand, we compare the carbon emission intensity before and after the selection, and test the low carbon contribution of the distribution mode. In summary, the decision target of the selection method proposed in the paper includes two aspects.

- To select the urban distribution mode;

- To reduce the carbon emissions intensity.

Second, construct the hierarchy analytic structural system. The alternatives to urban distribution mode include self-distribution mode, mutual distribution mode, third party distribution mode and common distribution mode. Influencing factors are mainly three comprehensive factors including enterprise scale strength, distribution service capability and social development trend, and the nine factors of subdivision level. As a result, a hierarchical analytic structure system is built and composed of the target layer, the criterion layer, the sub criterion layer and the plan layer. The symbol mark is given to each factor (for example, $M, Z 1, Z 2, Z 3, G 1, G 2$ ), so as to improve the construction efficiency of the fuzzy complementary judgment matrix. The dominance relationship among the factors is shown in Figure 1. 


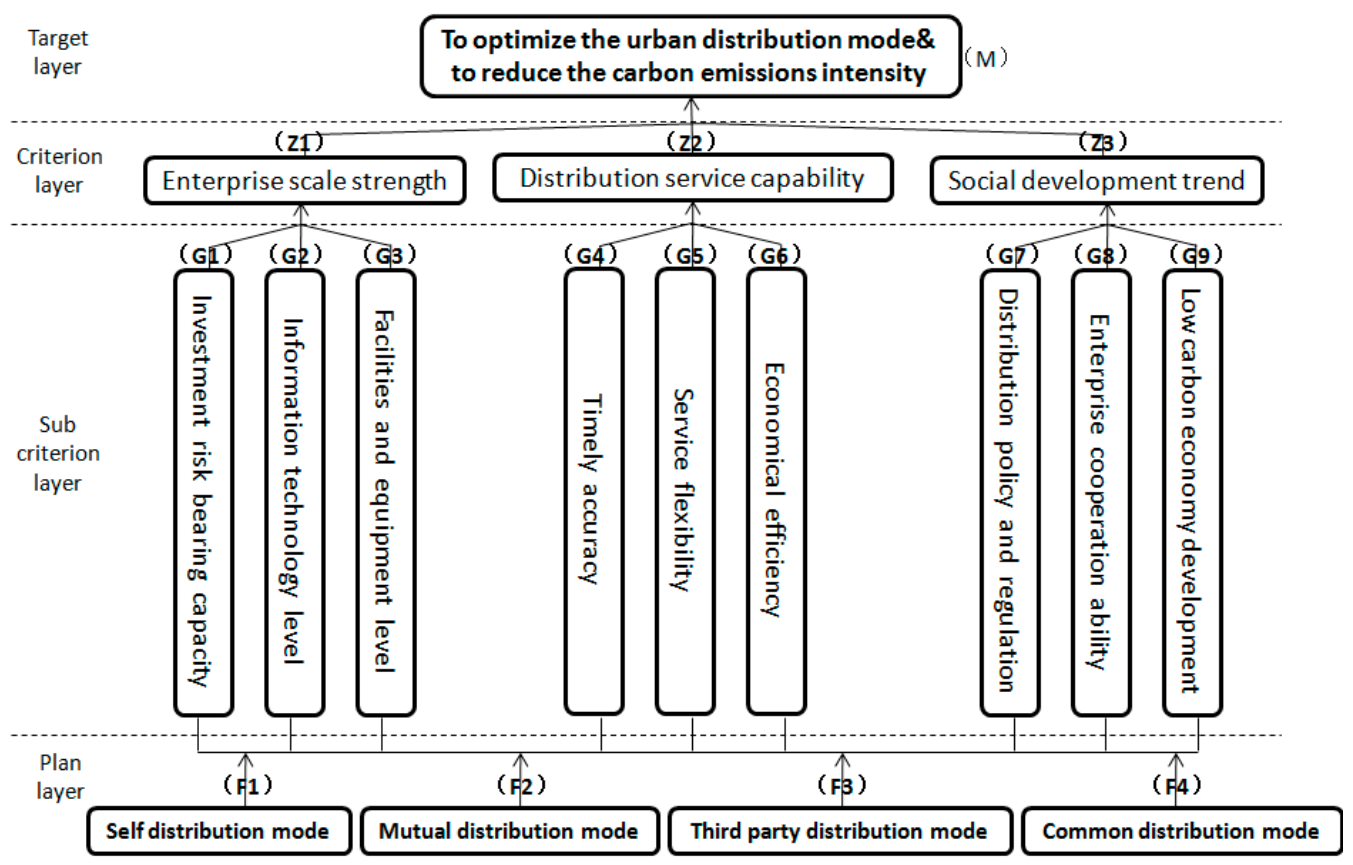

Figure 1. Urban distribution mode decision hierarchy analytic structure system.

Third, establish the fuzzy complementary judgment matrix. For decision makers, from the perspective of the same dominant factor in the upper level, it is more intuitive and easy to judge the relative importance of the two factors than directly giving their respective weights, which is the essence of the judgment matrix. According to the urban distribution mode, decision hierarchy analytic structure system is established. Urban distribution policy makers respectively construct the fuzzy complementary judgment matrix in order, from top to bottom then from left to right. In order to improve the practical application value of the decision result, enterprise urban distribution policy makers must thoroughly understand the situation of all aspects by the enterprise itself, and have an overall understanding of the external related development trend, in order to better judge the relative importance of the paired factors and provide more reasonable preference information.

Forth, check and improve the consistency in fuzzy complementary judgment matrix. In this paper, the requirement on the additive consistency of fuzzy judgment matrix is not very strict. Set the threshold value $\varepsilon=0.1$. If $\rho^{x_{q}^{m-1}} \leqslant \varepsilon$, it is considered that the fuzzy judgment matrix is consistent. Otherwise, it is necessary to adjust the elements of the fuzzy judgment matrix until the consistency condition is satisfied. This paper follows the principle that as far as possible to retain the preference information of the personnel, and only adjust the value of a pair of elements at a time.

Fifth, decide the hierarchical ranking. The calculation method is shown as Equation (9). $w_{i}^{x_{q}^{m-1}}$ represents the weight of the factor $x_{i}^{m}$ dominated by the factor $x_{q}^{m-1}$ in the upper layer.

$$
w_{i}^{x_{q}^{m-1}}=\beta^{\frac{1}{n} \sum_{j=1}^{n} c_{i j}^{x_{i}^{m-1}}} / \sum_{s=1}^{n} \beta^{\frac{1}{n} \sum_{j=1}^{n} c_{s j}^{x_{q}^{m-1}}} \quad(i \in N, \beta=2)
$$

On the basis of the hierarchical single ranking, the comprehensive weight of each alternative scheme is calculated, so as to make the decision accurately. The comprehensive weight calculation method is as follows. Assuming that this paper has calculated the weight vector of $k$ factors of the $m-1$ layer relative to the total target, the weight vector is $A^{m-1}=\left(a_{1}^{m-1}, a_{2}^{m-1}, \ldots, a_{k}^{m-1}\right)^{T}$, and the weight vector of $l$ factors of the $m$ layer dominated by the $q$ factor of the $m-1$ layer is obtained through the hierarchy single ranking. It is $b_{q}^{m}=\left(b_{1 q}^{m}, b_{2 q}^{m}, \ldots, b_{l q}^{m}\right)^{T}(q \leqslant k, n \leqslant l)$, and the 
corresponding weight of the factor is zero, which is not controlled by the $q$ factor of the $m-1$ layer. Supposing $B^{m}=\left(b_{1}^{m}, b_{2}^{m}, \ldots, b_{k}^{m}\right)$, then the calculation method of the weight vector in the $m$ layer relative to the total target is shown as Equation (10). The comprehensive weight of each scheme can be obtained by calculating the layer in order. The scheme whose weight is largest may be the optimal urban distribution mode suitable for the enterprise through the process of decision-making.

$$
A^{m}=B^{m} A^{m-1}
$$

Last, pilot distribution mode scheme and comparison of carbon emission intensity. This paper is based on the specific project, so it is necessary to put the research into practice. On one hand, through the industry association, there is a cooperative relationship between the project implementation unit and the enterprise. It contributes to pilot the new distribution mode for a particular category within a given period of time, collect the required activity data and revenue for the same period of last year. On the other hand, large to the country and Guangdong Province, small to Guangzhou City, the development of low carbon economy is the important theme currently or in the future. Whether the scheme can reduce the carbon emission intensity has become the focus of enterprise, and although the logistics industry is not included in the scope of Guangzhou City carbon emissions trading pilot, it is the key industry considered in the future. Reducing the carbon emission intensity is the responsibility of enterprise to develop the sustainable development.

Therefore, to obtain the most suitable distribution mode is not the same with the original method through the above judgment decision process. They will pilot urban distribution mode scheme in a specific period of time for a specific category. At the end of the pilot period, the activity data, revenue of the period and the same period of last year should be collected. The carbon emission intensity is calculated and compared. If the carbon emission intensity weakens to a certain extent, it shows that the urban distribution mode piloting has more significant low carbon benefits, so enterprises can consider the promotion of the distribution mode.

\subsection{Analysis on the Present Situation of the Guangzhou Distribution}

Urban distribution is a subsystem in the entire logistics system, which can provide users with direct logistics services and meet the needs of residents living in major livelihood projects. In February 2013, the Ministry of Transport, Ministry of Public Security, Ministry of Commerce and other seven ministries jointly issued "On strengthening and improving the urban distribution management". They planned to improve distribution infrastructure, urban distribution markets significantly and optimized body structure within five years. With the wide application of the urban distribution models, urban distribution vehicle traffic becomes more orderly and smooth, urban distribution operational efficiency improves certainly. Based on the "City of Guangzhou Logistics Development Plan (2014-2020)", this paper analyzes the distribution situation in Guangzhou City and the problems of building in urban distribution system. The analysis of the study will help enhance the public awareness of urban distribution situation for urban development.

Types of goods and freight distribution situation are as follows. The goods under city logistics are residents' living goods. According to "Guangzhou City Statistical Yearbook [37]" the statistical standards are divided into 25 categories, including feedstuffs, cotton, metal materials, wood and related products, chemical materials and products and other goods due to product attributes in downtown Guangzhou. At this stage, goods have not been established in urban Guangzhou logistics freight statistical system, each company has different statistical standards, so the city cannot get the logistics industry cargo data. According to a close relationship between logistics and business flow, from end to start the sale of goods, the use of the social retail sales data estimates Guangzhou city logistics freight data, the results are shown in Table 1. The calculation is completed in 2013, Guangzhou City Distribution volumes 44,490,600 t, 127.42\% increases compared to 2008, an average size of 4,154,600 t, average annual growth rate of $21.24 \%$. Distribution from the city spatial structure are the center 
four districts (Yuexiu, Tianhe, Liwan District, Haizhu District), Panyu District, Guangzhou Baiyun District and the city's largest urban logistics distribution are seen in Figure 1 and Table 2.

Since 2013, Guangzhou has become the first batch of urban distribution pilot city in China, it has been gradually carried out the plan of distribution pilot.

- According to the requirements of specific documents, it has selected fourteen logistics enterprises as urban distribution pilot enterprises and try to implement advanced distribution mode in these enterprises;

- Set up high standard professional fleet. It also has designed urban distribution logo with Guangzhou's characteristics, and introduced nearly 500 vans with unified identity. Vehicle weight is mainly not more than 2 tons, partly 2 tons to 5 tons, which provides hardware conditions for the realization of "centralized distribution and joint distribution" in the future;

- Combining with the actual production situation and taking into account the traffic pressure, it has developed reasonable traffic policy. In case that the traffic is not affected, give the pilot vehicle with a short time stop. According to the principle of "one car one card", make urban distribution pass for the pilot vehicle;

- Prepare and develop urban logistics;

- Establish development plan. On the basis of the current situation, make plan for public distribution node layout, distribution channel and public information platform, which are the preliminary preparation for the implementation of common distribution;

- Draft relevant standards for urban distribution, including "Standard for private parking spaces", "Specification for urban distribution service", "Specification for urban distribution center construction" and "Standard for common distribution operation".

In the 25 categories of distribution goods in Guangzhou City, there are eight categories of goods accounted for more than $93 \%$, shown in Figure 2. The specific content is shown as following.

\section{Distribution proportion of the main \\ distribution goods in Guangzhou City.}

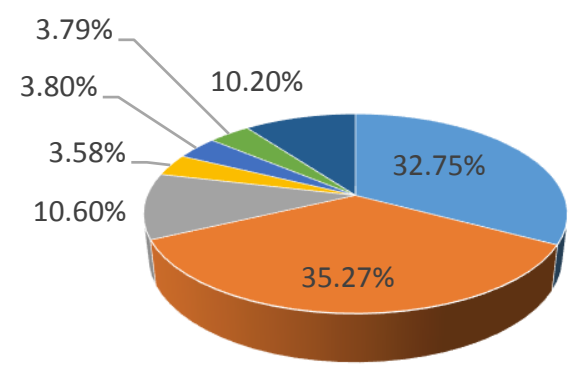

- petroleum and its products

- Food, beverages, tobacco and alcohol

- Others

- Accommodation catering services related distribution category

Figure 2. Distribution of the proportion of the main distribution goods of Guangzhou City.

- Food, beverages, tobacco and alcohol are three of the largest proportions among the distribution objects, $2.51 \%$ higher than the proportion of petroleum and its products. The situation of $35.27 \%$ shows that the most important function is to meet the living needs of the residents rather than the demand of industrial production.

- The proportion of petroleum and automobiles are $32.76 \%$ and $10.20 \%$ respectively. Mainly because the petrochemical manufacturing industry and automobile manufacturing industry are the two pillar industries in Guangzhou City and belong to heavy industry. 
- The freight volume of clothing, textiles, household appliances and audiovisual equipment, accommodation catering services related distribution category accounts for about $3.72 \%$, because the clothing wholesale industry, audio and video industry and catering service industry in Guangzhou City are relatively developed.

- The daily distribution freight volume of Chinese and western medicines accounts for about $2.16 \%$. To a certain extent, the large distribution quantity of daily necessities is related to the high proportion of the floating population. The health industry is more mature and people pay attention to the pension and health care, so the relatively distribution quantity is large.

Goods are distributed in some specific periods, shown in Figure 3.

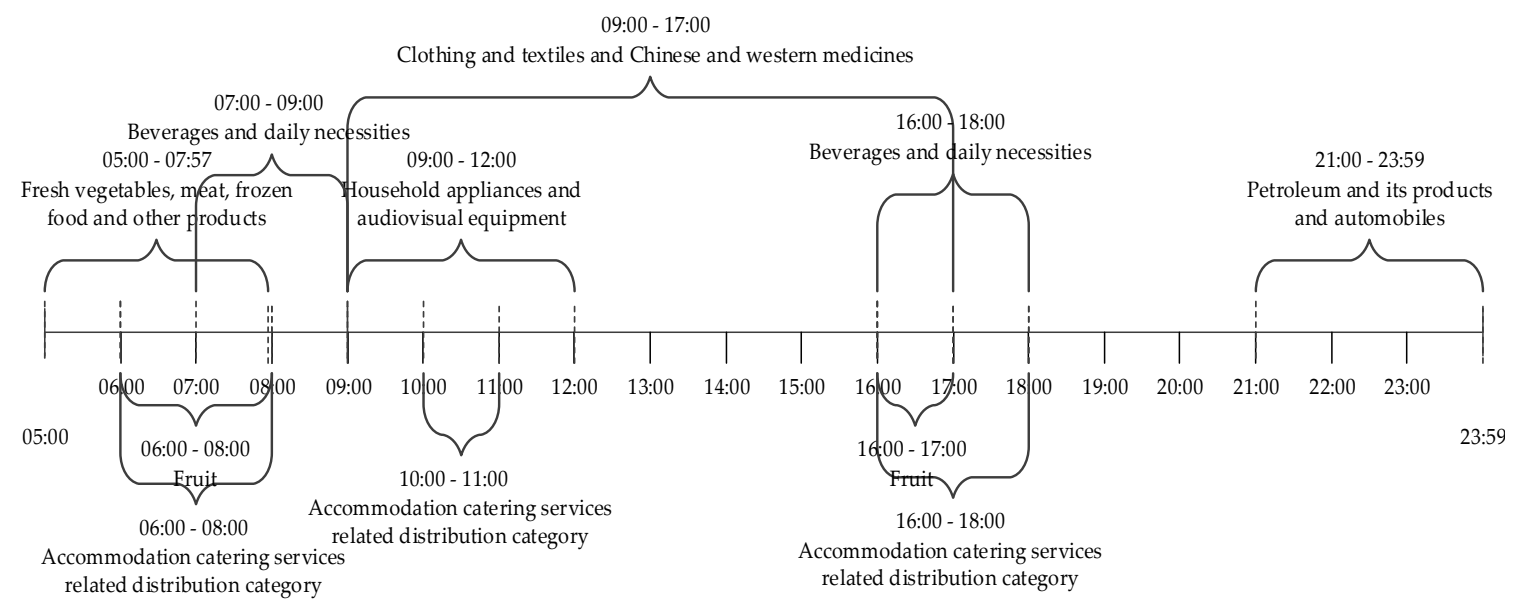

Figure 3. Main distribution period of eight kinds of goods in Guangzhou.

- The distribution period of fresh vegetables, meat, frozen food and other products of food, beverages, tobacco and alcohol are mainly concentrated in 5:00 A.M.-8:00 A.M. The distribution period of fruit is mainly concentrated from 6:00 A.M.-8:00 A.M. and 4:00 P.M.-5:00 P.M.

- The distribution periods of beverages and daily necessities are mainly concentrated in 7:00 A.M.-9:00 A.M. and 4:00 P.M.-6:00 P.M. It is more obvious at the weekend.

- The distribution period of clothing, textiles and medicines are relatively scattered, mainly during work hours of the day.

- The petroleum and automobiles have the characteristics of low distribution frequency and large capacity. The distribution period is mainly concentrated after 9:00 P.M.

- The distribution period of household appliances and audiovisual equipment is mainly concentrated in 9:00 A.M.-12:00 A.M.

- The distribution period of accommodation catering services related distribution category are mainly concentrated in 6:00 A.M.-8:00 A.M., 10:00 A.M.-11:00 A.M., and 4:00 P.M.-6:00 P.M., coinciding with the time of checking inn hotel and dining hours.

It is visible that in addition to petroleum and its products, automobiles, the distribution period of the other six major categories with the morning and evening peak. The policy of restricting the passage will significantly affect the distribution of these goods.

The distribution nodes are specific, the construction of all kinds of distribution nodes in Guangzhou City are shown in Figure 4. The overall distribution level is not high, but policy guidance is needed to build a more systematic distribution nodes network. Specific performance is as following. 


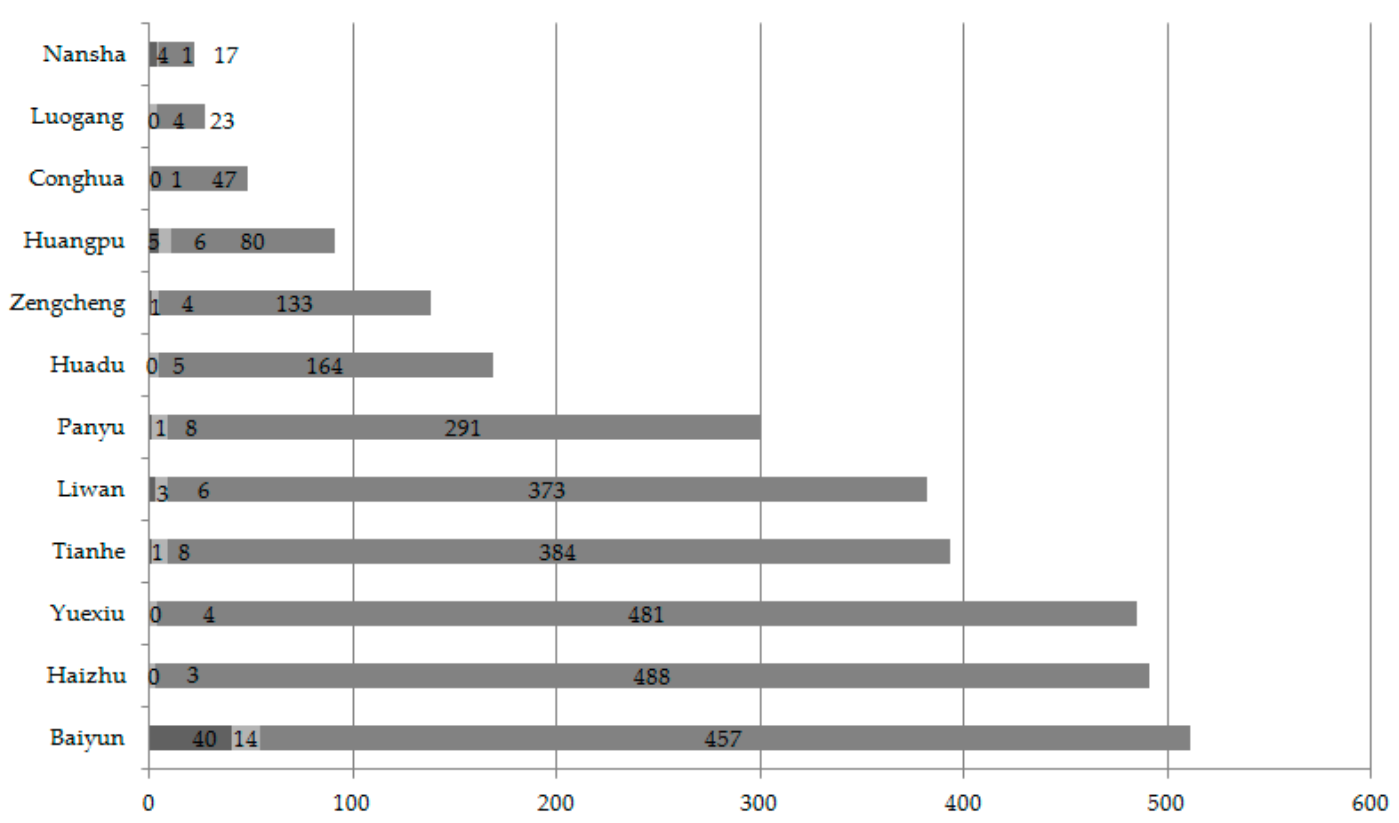

Figure 4. Construction of all kinds of distribution nodes in Guangzhou City.

- Three level nodes: In the three kinds of distribution nodes, the community distribution center occupies the largest proportion. However, it does not get reasonable planning and construction, and the overall size is small. Most of them are temporarily set up, and the function of the distribution node fails to meet the requirement of distribution.

- Two level nodes: The number of urban distribution centers is about seventy, but it mainly serves the customers, not providing other enterprises with distribution resources.

- First level node: The number of large logistics distribution base is less and the development is scattered. However, they generally achieve better operation effect, providing high-quality hardware and software basics for the effective operation. The shortage is that the comprehensive large-scale logistics distribution base has not been timely planned and constructed, which is the work focus in the future distribution development.

Urban distribution problems are as follows.

For the hardware problems, the urban logistics infrastructure is good enough, but still unable to form a highly efficient, rational urban distribution system. With the rising level of urbanization, the logistics industry gradually gets attention. Guangzhou's logistics industry starts in recent decades, but it lacks of the large-scale integrated urban distribution centers, the community center, commercial centers, commercial streets and community centers. Populated areas do not plan to open community distribution points, wholesale markets warehousing. In addition, logistics enclave relocation has not been set up independently. Professional distribution center node structure is incomplete, tobacco, salt, medicines and other goods distribution node lack of professional support.

Urban delivery vehicle standardization needs to be improved. Guangzhou City, as a large international city, the production of materials should meet people's daily lives and businesses of the daily production needs. It is predicted that by 2015 , Guangzhou needs more than 100,000 vehicles to provide logistics and distribution business. Thus, traffic conditions will face serious challenges. However, at this stage, with the launching of the pilot city, development and implementation of appropriate delivery vehicle standards are already on the right track, but the standardized delivery vehicle are used by less than 30\%, there is a large number of "Customer to Freight" vehicle.

For software problems, urban distribution faces "three difficult" problems on vehicle travel. There is a common problem in large cities, distribution vehicles have difficulties in parking, loading and unloading. Since Guangzhou commerce industry develops, with a large amount of vehicle 
ownership, the congestion situation is more serious. In order to reduce urban traffic congestion, truck limit line policies are imposed increasingly stringently. The policies aim to restrict access area to expand continually.

City distribution and information standardization improves. On the information level, the existing logistics information platform is imperfect in Guangzhou, because it lacks of inter-departmental communication and cooperation. Therefore, the information system platform becomes fragmented and cannot communicate with each other, which leads to information "islands", duplication and waste of resources. It is not conducive to communicate among enterprises, government, business and the market. Moreover, it hinders the improvement of logistics. On the level of standardization, standardization of logistics industry in Guangzhou City is low. Many of the standardizations follow national standards, few of them with modern logistics industry in Guangzhou City. Guangzhou currently is only available in some logistics aspects to carry out some studies and develops a corresponding standard. The lack of effective connection is not conducive to the development of the logistics industry standardization.

Lack of government support policies, the related support policies for urban distribution, such as land concessions, tax incentives, and financial subsidies, is insufficient in Guangzhou City. The government has not played the leading role in the development of urban distribution. Many companies reflect that there is a lack of financing support policies in Guangzhou City, and few of the incentive policies are introduced. At the same time, financial institutions have not designed ancillary financial products around the logistics industry, so that the services sector asset light logistics companies have difficulty in financing and operations.

\subsection{Determine the Main Research Types of Goods}

Based on the Guangzhou City, this paper studies the best urban distribution mode. The main types of distribution goods are numerous, and the proportion of the freight volume are quite different. Research on the distribution mode does not have practical significance. Due to the limited space, this article only studies limited types of goods. From the perspective of low carbon, it should focus on the research which distribution carbon emission intensity is higher. According to the definition of urban distribution carbon emission intensity, the carbon emission intensity of some goods is in direct proportion to the total amount, and is inversely proportional to the revenue. Under normal circumstances, the total amount of carbon emission is consistent with the change trend of freight volume. Therefore, the goods distribution whose freight volume is relatively large but revenue is not high, which will be the focus research object in this study.

According to the preliminary study, in the order of carbon emission intensity from large to small, the eight categories of goods are followed by:

(1) Food, beverages, tobacco and alcohol;

(2) Daily necessities;

(3) Accommodation catering services related distribution category;

(4) Petroleum and its products;

(5) Household appliances and audiovisual equipment;

(6) Clothing and textiles;

(7) Automobiles;

(8) Chinese and Western medicines.

We specifically choose the above nine variables affecting urban distribution model, measured on a nine-point scale using the following bands: strongly disagree; disagree, tend to disagree; average; tend to agree; agree, strongly agree. The maximum weight is given for "strongly agree" in the case of a favorable attitude and for "strongly disagree" in the case of an unfavorable attitude. Finally, we choose four groups including government policy makers, senior corporate managers, logistics experts and truck drivers as evaluation variable object, a total of 20 people, with their score average data as a basis for subsequent decisions. 
In the second phase, before we obtain the scores made by four groups of personnel, we carefully explain to them in detail the meaning and impact of the nine related variables, which aims to ensure that all respondents can understand. We interview government decision-makers, senior corporate manager, logistics experts and truck drivers each five people, let them fill out a corresponding questionnaire. Questionnaires are developed based on FAHP model, every problem is to compare the two standards. The survey is based on the overall perception of the situation to confirm the two standard weight. Then we will fill and correct the scores according to the consistency in the FAHP model.

Finally, the sensitivity analysis is examined to determine the impact of changes in the weights of the decision criteria. Next, this paper takes a number of representative enterprises as examples. Using the method proposed above and adopting Office Excel Microsoft as the auxiliary computing tool, we study the urban distribution mode of enterprises that operate these categories of goods, and re-determine the applicability of the existing urban distribution mode, so as to choose the best distribution mode and achieve the reduction of emission intensity. At the same time, in order to protect the business privacy, this article retains some sensitive information. The specific calculation process is detailed in the supplementary material.

\subsection{Comparison on Four kinds of Distribution}

There are the main four kinds of urban distribution. The comparisons are shown in Table 6, from the perspectives of logistics control, impact on the rest of the business, business connection degree, input costs, operating costs, delivery timeliness, efficiency of information feedback, the safety of the goods, customer experience, coverage, and the market supply and demand.

Table 6. Comparison on four kinds of distribution.

\begin{tabular}{|c|c|c|c|c|}
\hline Factors & Self-Distribution & $\begin{array}{c}\text { Mutual } \\
\text { Distribution }\end{array}$ & $\begin{array}{l}\text { Third-Party } \\
\text { Distribution }\end{array}$ & Joint Distribution \\
\hline Logistics Control & $\begin{array}{l}\text { Higher, all-the-way } \\
\text { tracking control }\end{array}$ & $\begin{array}{l}\text { High, all-the-way } \\
\text { tracking control }\end{array}$ & $\begin{array}{l}\text { Low, hardly } \\
\text { tracking control }\end{array}$ & $\begin{array}{c}\text { General, partly track } \\
\text { control }\end{array}$ \\
\hline $\begin{array}{l}\text { Impact on the Rest of } \\
\text { the Business }\end{array}$ & $\begin{array}{c}\text { Scattered resources on } \\
\text { other business }\end{array}$ & $\begin{array}{l}\text { General, partly } \\
\text { promote on other } \\
\text { business }\end{array}$ & $\begin{array}{l}\text { Expand the business } \\
\text { outside of logistics }\end{array}$ & $\begin{array}{l}\text { General, partly } \\
\text { promote other } \\
\text { business }\end{array}$ \\
\hline $\begin{array}{c}\text { Business Connection } \\
\text { Degree }\end{array}$ & $\begin{array}{l}\text { High, interface with } \\
\text { other parts preferably }\end{array}$ & $\begin{array}{l}\text { General, require high } \\
\text { informatization }\end{array}$ & Low & $\begin{array}{c}\text { Integrate operation } \\
\text { hard }\end{array}$ \\
\hline Input Costs & Upfront costs high & Upfront costs general & Upfront costs low & Upfront costs general \\
\hline Operating Costs & $\begin{array}{l}\text { General, recoup } \\
\text { funds fast }\end{array}$ & General & $\begin{array}{l}\text { High, difficult to } \\
\text { recoup funds }\end{array}$ & General \\
\hline Delivery Timeliness & $\begin{array}{c}\text { Strong, shorten the } \\
\text { delivery time }\end{array}$ & $\begin{array}{l}\text { Strong, deliver in } \\
\text { time }\end{array}$ & $\begin{array}{l}\text { Bad, deliver on } \\
\text { time hardly }\end{array}$ & $\begin{array}{l}\text { General, deliver } \\
\text { on time }\end{array}$ \\
\hline $\begin{array}{l}\text { Efficiency of } \\
\text { Information } \\
\text { Feedback }\end{array}$ & High & High & Sometimes delay & Sometimes delay \\
\hline $\begin{array}{l}\text { The Safety of the } \\
\text { Goods }\end{array}$ & $\begin{array}{l}\text { Higher, ensure } \\
\text { the safety }\end{array}$ & $\begin{array}{l}\text { High, almost ensure } \\
\text { the safety }\end{array}$ & $\begin{array}{l}\text { General, almost } \\
\text { ensure the safety }\end{array}$ & $\begin{array}{l}\text { Bad, damage } \\
\text { goods easily }\end{array}$ \\
\hline Customer Experience & $\begin{array}{l}\text { Ensure quality of } \\
\text { service, provide } \\
\text { personalized service }\end{array}$ & $\begin{array}{l}\text { High, provide } \\
\text { personalized service }\end{array}$ & $\begin{array}{l}\text { Third-party decides, } \\
\text { difficult to provide } \\
\text { higher service }\end{array}$ & $\begin{array}{c}\text { High, provide } \\
\text { personalized service }\end{array}$ \\
\hline Coverage & Lowest & Lower & High, many branches & Low \\
\hline $\begin{array}{l}\text { Market Supply } \\
\text { and Demand }\end{array}$ & $\begin{array}{l}\text { Obvious gap between } \\
\text { supply and demand }\end{array}$ & Respond timely & $\begin{array}{l}\text { Respond quickly } \\
\text { adjust the resources } \\
\text { allocation }\end{array}$ & $\begin{array}{l}\text { Difficult to quickly } \\
\text { respond to change }\end{array}$ \\
\hline
\end{tabular}




\section{Results and Discussion}

\subsection{Results and Discussion on the Urban Distribution Mode of Enterprise A}

Enterprise A has a number of brand drinks distribution rights in Guangzhou, provides supermarkets, retail stores and other business customers with complete sets of beverage distribution services, forming a wide range of consumer goods distribution network. After years of development, enterprise A has a mature distribution management and technical capabilities. It has built a large distribution center and fleet. The number of the vehicles is approaching five hundred, and it is a leading enterprise in the field of distribution in Guangzhou. It is visible that the distribution strategy of enterprise A is self-distribution mode, and the practice proves that the distribution mode is successful. However, as one of the survival rules of enterprises, enterprises must periodically re-judge and adjust the distribution development strategy to adapt to the economic and social development trend. Therefore, the urban distribution mode method proposed in this paper is also applicable to the enterprise A. By using the method, the comprehensive weight of each scheme is as following:

$$
W_{F}^{M}=(0.26438,0.24394,0.241725,0.249954)^{T}
$$

In conclusion, the administrators of distribution provide the preference information of each factor according to the comprehensive situation of its own strength and external environment. Using the improved FAHP proposed in this paper to carry out the related calculation, there are the following conclusions: the decision result of enterprise $\mathrm{A}$ is to maintain the original distribution mode, which shows that the development of self-distribution mode has a mature condition. It is a typical enterprise with self-distribution mode. For enterprise A, since ratio of self-distribution is much higher than other three kings of distribution, to optimize the urban distribution mode is not the optional method to develop low carbon economy, but it can reduce urban distribution carbon emission intensity through the introduction of clean energy vehicles, improving vehicle loading rate and distribution management level and other ways.

\subsection{Results and Discussion on the Urban Distribution Mode of Enterprise B and Enterprise $C$}

Enterprise B was founded in the early twenty-first century, located in the edge of Liwan District of Guangzhou City, where is near Foshan City. With more than ten years' experience of daily necessities wholesale sales, it has more than sixty brands of daily necessities distribution rights, and the purchase channel is stable with a price advantage. The company offers distribution services autonomously, achieving sales and distribution integration. However, sometimes enterprise B cannot meet some customer demand for the rare brand daily necessities.

In order to improve the customer satisfaction and loyalty, considering its own interests and market channels news, enterprise $B$ learns that daily necessities distribution enterprise $C$ is near the junction of Baiyun District Airport Expressway and has the distribution rights for these rare brands. At the same time, enterprise B finds that there is almost no overlap between the daily necessities types that enterprise $\mathrm{C}$ operates and its business scope. In addition, enterprise $\mathrm{C}$ also belongs to the integration of sales and distribution. To a certain extent, it reflects the universality of self-distribution mode in Guangzhou City. Therefore, through the cooperation with enterprise C, they share the customer resources and open up their own market scope, but still maintain the original distribution rights, providing customers with the purchase channels and distribution services autonomously. However, due to the far distance from the new development customers, the self-distribution mode of the two enterprises has not played its due role, and fails to timely supply, which results customers out of stock frequently.

Therefore, enterprise $B$ and enterprise $C$ need to re-judge the urban distribution mode, which can use the method of low carbon urban distribution mode to carry out optimization and analysis. Using the method proposed in this paper, we have the following results: For enterprise B, 
the comprehensive weight of each scheme is: $\left(W_{F}^{M}\right)_{B}=(0.244289,0.252463,0.251449,0.251799)^{T}$; For enterprise $C$, the comprehensive weight of each scheme is:

$$
\left(W_{F}^{M}\right)_{C}=(0.237458,0.261302,0.240931,0.260309)^{T}
$$

Therefore, the two companies have come to the conclusion that the existing urban distribution mode does not meet the needs of enterprises and social development. At present, the development of common distribution mode does not have the mature conditions, and the use of third party distribution mode has little attraction for enterprises with self-built distribution system. Therefore, mutual distribution mode is the most suitable distribution mode after the judgment and analysis of enterprise $B$ and enterprise $C$ while the common distribution ranks second. Common distribution has the advantages of high distribution efficiency and low distribution cost. However, it has the risk of commercial safety and benefit distribution. When the information technology level, cooperation ability, distribution policy and regulation improve, the most suitable distribution mode may become common distribution, since the ratio of mutual distribution is not far higher than that of common distribution urban distribution mode. At the same time, through the process of decision analysis, it concludes that mutual distribution mode is a better urban distribution mode for the two companies. Therefore, for the enterprise whose essence is the pursuit of interests, it is feasible to use mutual distribution mode between enterprise $B$ and enterprise $C$. They use each other's distribution resources and systems in the economic scope, then improve the customers' logistics distribution experience. With the mutual distribution, the enterprises can expand its size and distribution scope without investing lots of money and manpower. However, mutual distribution requires a higher level of informatization and coordination capacity of enterprises.

As the results are shown, the share of self-distribution and the common distribution are similar in enterprise A, but enterprise A prefers self-distribution to common distribution. As for the enterprises $\mathrm{B}$ and $\mathrm{C}$, the priority of mutual distribution and common distribution is also very close, but enterprise $B$ and $C$ prefer mutual distribution more. However, in terms of business and government perspective, the common distribution is more efficient and cost-saving. From the perspective of enterprise, common distribution enables distribution operations to achieve economies of scale, improves the efficiency of distribution and reduces operating costs. Besides, with common distribution, enterprise does not need to invest a lot of money, equipment, land, labor, etc., it can save resources for the enterprise. Therefore, enterprise can focus on the development of core-business, which can promote the growth of enterprises, expand the scope of the market, eliminate the original closed sales-network and finally build a coexistence environment.

With the guidance of low carbon economy, the government hopes to achieve common distribution in urban distribution. Common distribution benefits a lot, such as: reduce the total amount of vehicles and the discharge phenomenon in public traffic and improve transportation situation. By the centralized processing, vehicle loading rate is improved, space-saving and human resources are saving, which improves the business environment and the overall quality of social life. However, common distribution faces several problems, such as the capitation fee of logistics cost and business secrets. Besides, there is a gap scale on business district and business sense, which is difficult to reconcile.

Therefore, we give advice to the government. On one hand, the government should accelerate the construction of infrastructure and support some distribution enterprises to establish large-scale distribution centers. As for the household living products, the government can offer subsidies or reduce operating costs in the distribution centers. The government should also encourage more enterprises to use the distribution centers invested by government. At the same time, we must make the rule of fair cost-sharing and the protection of commercial confidential so that enterprises store the goods trustingly. After forming the goodwill and the dependence on large-scale distribution centers, it promotes the development of common distribution. On the other hand, at this stage, the government can encourage large companies to continually integrate resources and expand the scale of the formation of self-distribution. On account of the middle and small enterprises, the government should encourage 
mutual cooperation between them, constantly improving the process of information in logistics system and reduce the expenditure of human cost. Through the cooperation, the enterprises build a large and mutual distribution system, aims to achieve cost savings and distribution objectives.

Details of the pilot process, data collection and calculation are in the supplementary material. The pilot result is that the carbon emission intensity of enterprises $B$ and enterprise $C$ decreases by 11.28 percentage points than that in the same period last year. It is proved that the mutual distribution mode is more in line with the development trend of low carbon economy than the self-distribution mode. Even if the decrease degree by $11.28 \%$ has a significant distance with China's carbon emission intensity reduction target in 2030 by $60 \%-65 \%$, but it is also a positive exploration of low carbon in the field of urban distribution. In the future, with the implementation of preferential policies and measures, it will be able to get a greater degree of reduction for the improvement. If enterprise $B$ and enterprise $\mathrm{C}$ use mutual distribution mode, to a certain extent, it can provide commercial activities with efficient distribution experience. It is consistent with the development trend of low carbon economy and is worth promoting the city distribution mode. More importantly, the results show that the low carbon urban distribution mode method can effectively guide enterprises to focus on climate change issues develop low carbon urban distribution, consciously undertake carbon emission responsibility and conduct carbon disclosure.

\section{Conclusions}

This paper studies the optimum urban distribution mode under low carbon economy, and takes Guangzhou City as an example to make a more specific analysis and research. The low carbon urban distribution mode method proposed in this paper provides a theoretical reference for enterprises to adopt low carbon, more environmentally and friendly urban distribution mode, and promote the transformation and upgrading of urban distribution industry with practical application value. The main research work of this paper is summarized as follows.

- On the basis of the existing research, the consistency checking and improved algorithm of fuzzy judgment matrix are optimized, the derivation process and the principle of the algorithm are described in detail, and the efficiency of the algorithm improves.

- It is considered that the urban distribution mode needs to form from repeated exploration and practice, which cannot be designed without foundation. Four kinds of mature distribution modes have been analyzed: self-distribution mode, mutual distribution mode, third party distribution mode and common distribution mode.

- Combined with other scholar's research results and the characteristics of urban distribution, this paper systematically analyzes the influencing factors of urban distribution modes, adding the factor of low carbon economy development to the range of the influencing factors, and build up a more targeted influencing factor system composed of nine sub factors.

- Put forward carbon accounting method, which is suitable for urban distribution. Analyze the general process of urban distribution and define the boundaries of the carbon footprint. Determine emission inventory and build the carbon accounting model composed of two parts: the direct and indirect emissions, point out that there is a close relationship between the active data collection and the result of the emission inventory analysis; Propose using indicators-urban distribution carbon emission intensity to measure the low carbon benefit of the scheme.

- Propose the method of low carbon urban distribution mode based on FAHP. Fully integrate the previous study of the influencing factors on urban distribution mode selection, fuzzy analytic hierarchy process, urban distribution carbon accounting methods and other researches, which totally contain seven steps.

- From the following four aspects: administration department work progress, main distribution object, main distribution period and distribution node, this paper analyzes the situation of the development of Guangzhou City. 
- Based on the previous research, determine the three categories as the focus to research: food, beverages, tobacco and alcohol and daily necessities.

- Taking two kinds of enterprises as an example, beverage and daily necessities, the analysis is based on the low carbon urban distribution mode method proposed in this paper. Enterprises distribution management personnel provide preference information, and then fuzzy complementary judgment matrix related operation is carried out. The results show that the method is helpful to promote enterprises to develop low carbon urban distribution, consciously undertake the carbon emissions responsibility and conduct carbon disclosure.

In addition, due to the limited capability of the author, in the specific application of the low carbon urban distribution mode decision method, the research objects are limited in beverage and daily necessities, but not in the consumer goods closer to the people's livelihood, like fresh food, clothing, etc. The application research of these aspects can be more considered in future research. At the same time, in the research of urban distribution carbon accounting method, this paper only refers to the method provided by "2006 IPCC Guidelines for National Greenhouse Gas Inventories" [28] to build a more ideal and simple model, without considering the vehicle speed, emission control technology, temperature and other factors that affect the carbon emissions, innovative research is required in the future for further research in this area.

Supplementary Materials: Details of the pilot process, data collection and calculation are available online at www.mdpi.com/2071-1050/8/7/673/s1, Table S1: Fuzzy judgment matrix dominated by target M; Table S2: Fuzzy judgment matrix dominated by rule Z1; Table S3: Fuzzy judgment matrix dominated by rule Z2; Table S4: Fuzzy judgment matrix dominated by rule Z3; Table S5: Fuzzy judgment matrix dominated by rule G1; Table S6: Fuzzy judgment matrix dominated by rule G2; Table S7: Fuzzy judgment matrix dominated by rule G3; Table S8: Fuzzy judgment matrix dominated by rule G4; Table S9: Fuzzy judgment matrix dominated by rule G5; Table S10: Fuzzy judgment matrix dominated by rule G6; Table S11: Fuzzy judgment matrix dominated by rule G7; Table S12: Fuzzy judgment matrix dominated by rule G8; Table S13: Fuzzy judgment matrix dominated by rule G9.

Acknowledgments: This work was supported by National Natural Science Foundation of China (71572058), Soft Science Program of Guangdong Province (2014A070703007, 2015A070704008), the Fundamental Research Funds for the Central Universities, SCUT (2015ZZ057).

Author Contributions: Lei Yang conceived the model and designed the experiments; Yiji Cai and Jiahui Hong wrote the paper; Yongqiang Shi and Zhiyong Zhang revised the whole details.

Conflicts of Interest: The authors declare no conflict of interest.

\section{References and Notes}

1. Nations, Department of Economic and Social Affairs. Population Division: World Urbanization Prospects, the 2011 Revision; Final Report with Annex Tables; United Nations: New York, NY, USA, 2012.

2. Waldhoff, S.T.; Fawcett, A.A. Can developed economies combat dangerous anthropogenic climate change without near-term reductions from developing economies? Clim. Chang. 2011, 107, 635-641. [CrossRef]

3. Faccio, M.; Gamberi, M. New City Logistics Paradigm: From the "Last Mile" to the "Last 50 Miles" Sustainable Distribution. Sustainability 2015, 7, 14873-14894. [CrossRef]

4. Bazan, E.; Jaber, M.Y.; Zanoni, S. A review of mathematical inventory models for reverse logistics and the future of its modeling: An environmental perspective. Appl. Math. Model. 2016, 40, 4151-4178. [CrossRef]

5. Ayvaz, B.; Bolat, B.; Aydın, N. Stochastic reverse logistics network design for waste of electrical and electronic equipment. Resour. Conserv. Recy. 2015, 104, 391-404. [CrossRef]

6. Alshamsi, A.; Diabat, A. A reverse logistics network design. J. Manuf. Syst. 2015, 37, 589-598. [CrossRef]

7. Kannan, D.; Diabat, A.; Alrefaei, M.; Govindan, K.; Yong, G. A carbon footprint based reverse logistics network design model. Resour. Conserv. Recy. 2012, 67, 75-79. [CrossRef]

8. Tang, S.; Wang, W.; Yan, H.; Hao, G. Low carbon logistics: Reducing shipment frequency to cut carbon emissions. Int. J. Prod. Econ. 2015, 164, 339-350. [CrossRef]

9. Lee, K.; Wu, Y. Integrating sustainability performance measurement into logistics and supply networks: A multi-methodological approach. Br. Account. Rev. 2014, 46, 361-378. [CrossRef]

10. Choudhary, A.; Sarkar, S.; Settur, S.; Tiwari, M.K. A carbon market sensitive model for integrated forward-reverse logistics. Int. J. Prod. Econ. 2015, 164, 433-444. [CrossRef] 
11. Delivand, M.K.; Cammerino, A.R.B.; Garofalo, P.; Monteleone, M. Optimal locations of bioenergy facilities, biomass spatial availability, logistics costs and GHG (greenhouse gas) emissions: A case study on electricity productions in South Italy. J. Clean. Prod. 2015, 99, 129-139. [CrossRef]

12. Ugarte, G.M.; Golden, J.S.; Dooley, K.J. Lean versus green: The impact of lean logistics on greenhouse gas emissions in consumer goods supply chains. J. Purch. Supply Mag. 2015, 9, 1-12. [CrossRef]

13. Suzuki, Y. A new truck-routing approach for reducing fuel consumption and pollutants emission. Transp. Res. D Trans. Environ. 2011, 16, 73-77. [CrossRef]

14. Ćirović, G.; Pamučar, D.; Božanić, D. Green logistic vehicle routing problem: Routing light delivery vehicles in urban areas using a neuro-fuzzy model. Expert Syst. Appl. 2014, 41, 4245-4258. [CrossRef]

15. Zhao, P.; Liu, B.; Xu, L.; Wan, D. Location Optimization of Multidistribution Centers Based on Low-Carbon Constraints. Discrete Dyn. Nat. Soc. 2013, 2013,1-6. [CrossRef]

16. Pamučar, D.; Gigović, L.; Ćirović, G.; Regodić, M. Transport spatial model for the definition of green routes for city logistics centers. Environ. Impact Assess. Rev. 2016, 56, 72-87. [CrossRef]

17. Taskhiri, M.S.; Garbs, M.; Geldermann, J. Sustainable logistics network for wood flow considering cascade utilisation. J. Clean. Prod. 2015, 110, 1-15. [CrossRef]

18. Yang, J.; Guo, J.; Ma, S. Low-carbon city logistics distribution network design with resource deployment. J. Clean. Prod. 2016, 119, 223-228. [CrossRef]

19. Duan, H.; Zhu, L.; Fan, Y. Optimal carbon taxes in carbon-constrained China: A logistic-induced energy economic hybrid model. Energy 2014, 69, 345-356. [CrossRef]

20. Walker, G.; Manson, A. Telematics, urban freight logistics and low carbon road networks. J. Trans. Geogr. 2014, 37, 74-81. [CrossRef]

21. Mohareb, E.A.; Kennedy, C.A. Scenarios of technology adoption towards low-carbon cities. Energy Policy 2014, 66, 685-693. [CrossRef]

22. Huang, Y.; Xia, B.; Yang, L. Relationship Study on Land Use Spatial Distribution Structure and Energy-Related Carbon Emission Intensity in Different Land Use Types of Guangdong, China, 1996-2008. Sci. World J. 2013, 2013, 1-15. [CrossRef] [PubMed]

23. Xiao, F.; Hu, Z.; Wang, K.; Fu, P. Spatial Distribution of Energy Consumption and Carbon Emission of Regional Logistics. Sustainability 2015, 7, 9140-9159. [CrossRef]

24. Xiu, G.; Chen, X. The Third Party Logistics Supplier Selection and Evaluation. J. Softw. 2012, 7, $1783-1790$. [CrossRef]

25. Awasthi, A.; Chauhan, S.S. A hybrid approach integrating Affinity Diagram, AHP and fuzzy TOPSIS for sustainable city logistics planning. Appl. Math. Model. 2012, 36, 573-584. [CrossRef]

26. Senthil, S.; Srirangacharyulu, B.; Ramesh, A. A robust hybrid multi-criteria decision making methodology for contractor evaluation and selection in third-party reverse logistics. Expert Syst. Appl. 2014, 41, 50-58. [CrossRef]

27. Bouzon, M.; Govindan, K.; Rodriguez, C.M.T.; Campos, L.M.S. Identification and analysis of reverse logistics barriers using fuzzy Delphi method and AHP. Resour. Conser. Recycl. 2015, 108, 182-197. [CrossRef]

28. Eggleston, H.S.; Buendia, L.; Miwa, K.; Ngare, T.; Tanabe, K. 2006 IPCC Guidelines for National Greenhouse; IPCC/IGES: Hayama, Japan, 2006.

29. Data from the 2006 IPCC national greenhouse gas list. In the first chapter of the second volume, table 1.4.

30. Data from the provincial greenhouse gas inventory preparation guide. On table 1.7.

31. Calculating formula for "the $\mathrm{CO}_{2}$ emission factor $=$ unit the carbon content of calorific value * carbon oxidation rate *44/12".

32. Data from the 2006 IPCC national greenhouse gas list. In the third chapter of the second volume, table 3.2.2.

33. Data from "the comprehensive energy consumption calculation in GB/T 2589-2008". On the appendix A.

34. Data from the 2006 IPCC national greenhouse gas list guide. In the first chapter of the second volume, table 1.2.

35. Data from the UN's intergovernmental panel on climate change of the IPCC fourth assessment report.

36. Data from south China regional power grid baseline emission factor in EFOM regional.

37. The Second National Economic Census Leading Group Office in Guangzhou. Guangzhou City Statistical Yearbook; The Second National Economic Census Leading Group Office: Guangzhou, China, 2008.

(C) 2016 by the authors; licensee MDPI, Basel, Switzerland. This article is an open access article distributed under the terms and conditions of the Creative Commons Attribution (CC-BY) license (http://creativecommons.org/licenses/by/4.0/). 